\title{
Cannabinoid 1 and Transient Receptor Potential Vanilloid 1 Receptors Discretely Modulate Evoked Glutamate Separately from Spontaneous Glutamate Transmission
}

\author{
기 Jessica A. Fawley, Mackenzie E. Hofmann, and \Michael C. Andresen \\ Department of Physiology and Pharmacology, Oregon Health and Science University, Portland, Oregon 97239
}

\begin{abstract}
Action potentials trigger synaptic terminals to synchronously release vesicles, but some vesicles release spontaneously. G-proteincoupled receptors (GPCRs) can modulate both of these processes. At cranial primary afferent terminals, the GPCR cannabinoid $1\left(\mathrm{CB}_{1}\right)$ is often coexpressed with transient receptor potential vanilloid 1 (TRPV1), a nonselective cation channel present on most afferents. Here we tested whether $\mathrm{CB}_{1}$ activation modulates synchronous, action potential-evoked (eEPSCs) and/or spontaneous (sEPSCs) EPSCs at solitary tract nucleus neurons. In rat horizontal brainstem slices, activation of solitary tract (ST) primary afferents generated ST-eEPSCs that were rapidly and reversibly inhibited from most afferents by activation of $\mathrm{CB}_{1}$ with arachidonyl-2'-chloroethylamide (ACEA) or WIN $\quad 55,212-2 \quad[R$-(+)-(2,3-dihydro-5-methyl-3-[(4-morpholinyl)methyl]pyrrolo[1,2,3-de]-1,4-benzoxazin-6-yl)(1-naphthalenyl) methanone monomethanesulfonate]. The $\mathrm{CB}_{1}$ antagonist/inverse agonist AM251 [N-1-(2,4-dichlorophenyl)-5-(4-iodophenyl)-4methyl- $N$-1-piperidinyl-1H-pyrazole-3-carboxamide] blocked these responses. Despite profound depression of ST-eEPSCs during $\mathrm{CB}_{1}$ activation, sEPSCs in these same neurons were unaltered. Changes in temperature changed sEPSC frequency only from TRPV $1^{+}$afferents (i.e., thermal sEPSC responses only occurred in TRPV $1^{+}$afferents). $\mathrm{CB}_{1}$ activation failed to alter these thermal sEPSC responses. However, the endogenous arachidonate metabolite $N$-arachidonyldopamine (NADA) promiscuously activated both $\mathrm{CB}_{1}$ and TRPV1 receptors. NADA inhibited ST-eEPSCs while simultaneously increasing sEPSC frequency, and thermally triggered sEPSC increases in neurons with TRPV1 ${ }^{+}$afferents. We found no evidence for $\mathrm{CB}_{1} / \mathrm{TRPV} 1$ interactions suggesting independent regulation of two separate vesicle pools. Together, these data demonstrate that action potential-evoked synchronous glutamate release is modulated separately from TRPV1-mediated glutamate release despite coexistence in the same central terminations. This two-pool arrangement allows independent and opposite modulation of glutamate release by single lipid metabolites.
\end{abstract}

Key words: CB1; NADA; NTS; TRPV1; vesicle pool

\section{Introduction}

Synaptic vesicles undergo spontaneous release of their neurotransmitter, and this process was long considered to represent an infrequent, stochastic fusion of primed vesicles from a readily releasable pool (Katz, 1971; Kaeser and Regehr, 2014). For evoked release, activation of voltage-activated calcium channels (VACCs) allows calcium to enter the terminal and bind to synaptotagmin, which activates a core fusion cascade that triggers vesicle exocytosis (Südhof, 2013). Emerging evidence suggests that spontaneous release from some terminals may arise from a separately regulated, unique vesicle pool (Sara et al., 2005, 2011; Atasoy et al., 2008; Wasser and Kavalali, 2009; Peters et al., 2010).

Received Jan. 22, 2014; revised May 7, 2014; accepted May 9, 2014.

Author contributions: J.A.F. and M.C.A. designed research; J.A.F. and M.E.H. performed research; J.A.F. analyzed data; J.A.F. wrote the paper.

This work was supported by National Institutes of Health Grant HL-105703 (M.C.A.).

The authors declare no competing financial interests.

Correspondence should be addressed to Dr. Jessica A. Fawley, Department of Physiology and Pharmacology, Oregon Health and Science University, Portland, OR 97239-3098. E-mail: fawley.jessica@gmail.com.

DOI:10.1523/JNEUROSCI.0315-14.2014

Copyright $\odot 2014$ the authors $\quad 0270-6474 / 14 / 348324-09 \$ 15.00 / 0$
The existence of multiple sources of intraterminal calcium offers the potential for separately regulated modes of neurotransmitter release.

Second-order solitary tract nucleus (NTS) neurons receive solitary tract (ST) afferent inputs that either express transient receptor potential vanilloid $1\left(\mathrm{TRPV}^{+}\right)$or do not (TRPV1 ${ }^{-}$; Doyle et al., 2002; Jin et al., 2004; Laaris and Weinreich, 2007). Shocks to the ST activate afferent axons that trigger synchronous release of glutamate [ST-evoked EPSCs (eEPSCs)], a process that is indistinguishable between TRPV1 ${ }^{+}$and TRPV1 ${ }^{-}$afferents (Bailey et al., 2006b; Andresen and Peters, 2008). Despite similarities in eEPSCs, TRPV1 ${ }^{+}$afferents display 10 -fold higher spontaneous release rates [spontaneous EPSCs (sEPSCs)] than $\mathrm{TRPV}^{-}{ }^{-}$afferents, and these events arise from a vesicle pool independent of the evoked pool (Peters et al., 2010). Most ST afferents are TRPV $1^{+}$, and their sEPSC rates closely track temperature in the physiological range (Peters et al., 2010; Shoudai et al., 2010). This thermally driven glutamate release persists when calcium entry through VACCs is blocked (Shoudai et al., 2010; Fawley et al., 2011). This indicates that different sources of calcium independently mobilize separate subsets of glutamate vesicles in ST afferents. 
G-protein-coupled receptors (GPCRs) often modify the vesicle release process through actions at VACCs, adenylyl cyclase, and/or vesicle fusion proteins (Yoon et al., 2007; Brown and Sihra, 2008). $\mathrm{CB}_{1}$ receptors are one of the most common GPCRs in the CNS and are activated by endocannabinoids derived from lipid metabolites. Natural endocannabinoids closely resemble the chemical structure of vanilloid agonists and can also activate TRPV1 (Pertwee et al., 2010; Di Marzo and De Petrocellis, 2012). $\mathrm{CB}_{1}$ and endogenous ligands are coexpressed with TRPV1 in the CNS (Cristino et al., 2006, 2008). The synaptic transmission of TRPV ${ }^{+}$and TRPV1 ${ }^{-}$ST afferents thus serves as a unique model to assess $\mathrm{CB}_{1} / \mathrm{TRPV} 1$ interactions in the release of glutamate.

Here we tested whether $\mathrm{CB}_{1}$ receptors similarly affected ST-eEPSCs and sEPSCs. $\mathrm{CB}_{1}$ activation by arachidonyl-2'-chloroethylamide (ACEA) or WIN 55,212-2 [R-(+)-(2,3-dihydro-5-methyl3-[(4-morpholinyl)methyl]pyrrolo[1,2,3-de]-1,4-benzoxazin-6-yl) (1-naphthalenyl) methanone monomethanesulfonate] (WIN) discretely depressed ST-eEPSCs from TRPV $1^{+}$and TRPV1 ${ }^{-}$afferents without altering the basal sEPSC rates or thermal modulation of sEPSCs from the same afferents. However, $N$-arachidonyldopamine (NADA), an arachidonate derivative (Bisogno et al., 2000; Huang et al., 2002), inhibited ST-eEPSCs via $\mathrm{CB}_{1}$ activation regardless of TRPV1 expression but facilitated both spontaneous and thermal release only from TRPV ${ }^{+}$afferents. Thus, presynaptic $\mathrm{CB}_{1}$ in $\mathrm{ST}$ terminals modified the action potential-evoked release cascade without affecting the release machinery regulating spontaneous release. These results demonstrate a separate and independent regulation of glutamate release from the different vesicle pools without evidence of interactions. The compartmentalization of vesicle pools imparts this synapse with discrete signaling from different pools of a single neurotransmitter.

\section{Materials and Methods}

All animal procedures were approved by the Institutional Animal Care and Use Committee and conform to the National Institutes of Health guidelines. Male Sprague Dawley rats (150-250 g; Charles River) were used. Brains were removed under deep isoflurane anesthesia (5\%), and hindbrain slices were prepared as described previously (Doyle and Andresen, 2001). Briefly, a wedge of ventral brainstem was removed to tilt the hindbrain so that horizontal slices $(250 \mu \mathrm{m})$ contained the ST in the same plane as cell bodies in the caudal NTS (VT-1000S vibrating microtome from Leica; and sapphire blade from Delaware Diamond Knives). Slices were submerged in a perfusion chamber in an artificial CSF (ACSF) composed of the following (in mM): $125 \mathrm{NaCl}, 3 \mathrm{KCl}, 1.2$ $\mathrm{KH}_{2} \mathrm{PO}_{4}, 1.2 \mathrm{MgSO}_{4}, 25 \mathrm{NaHCO}_{3}, 10$ glucose, and $2 \mathrm{CaCl}_{2}$, ph 7.4 (bubbled with $95 \% \mathrm{O}_{2} / 5 \% \mathrm{CO}_{2}$ ). The chamber was continuously perfused $\left(1.5-2 \mathrm{ml} / \mathrm{min}\right.$ ) with ACSF with the temperature held at $32^{\circ} \mathrm{C}$ within $1^{\circ} \mathrm{C}$ using an inline heating system (Cell MicroControls). Bath temperature was continuously measured.

Patch-clamp recording. Patch pipettes (2.0-3.6 M $\Omega$ ) were pulled from borosilicate glass and filled with the following (in $\mathrm{mm}$ ): $6 \mathrm{NaCl}, 4$ $\mathrm{NaOH}, 130 \mathrm{~K}$-gluconate, 11 EGTA, $2 \mathrm{CaCl}_{2}, 2 \mathrm{MgCl}_{2}, 10 \mathrm{HEPES}, 2 \mathrm{Na}_{2}$ ATP, and $0.2 \mathrm{Na}_{2}$ GTP, pH adjusted to 7.3-7.32. NTS neurons were visualized using infrared differential interference contrast optics (Zeiss Axioskop FS2) and selected within $\pm 250 \mu \mathrm{m}$ rostrocaudal to the caudal end of the fourth ventricle and medial to the ST. Neurons were voltage clamped ( $-60 \mathrm{mV}$; Multiclamp 700B; Molecular Devices), and synaptic currents were sampled at $20 \mathrm{kHz}$ and filtered at $6 \mathrm{kHz}$ using pClamp 9.2 software (Molecular Devices). Liquid junction potentials were not corrected. The $\mathrm{GABA}_{\mathrm{A}}$ receptor antagonist gabazine (SR-95531 [2-(3-carboxypropyl)3-amino-6-(4-methoxyphenyl)pyridazinium bromide]; $3 \mu \mathrm{M}$ ) was present in all experiments. Drugs were purchased from Tocris Bioscience (R\&D Systems) or Caymen Chemical. All drugs except gabazine (dissolved in purified water) were dissolved in $100 \%$ ethanol so that the final concentration of ethanol in ACSF did not exceed $2 \mu \mathrm{l} / \mathrm{ml}$. Ethanol vehicle at this concen- tration did not alter ST-eEPSC amplitudes ( $p=0.2, n=7)$ or sEPSC frequencies $(p=0.3, n=7)$.

$S T$-eEPSCs define second-order neurons. A concentric bipolar stimulating electrode (200 $\mu \mathrm{m}$ outer tip diameter; Frederick Haer) was placed on the ST $>1 \mathrm{~mm}$ from the recorded neuron, and minimal-intensity, constant-current shocks were delivered ( 5 stimuli at $50 \mathrm{~Hz}$ every $6 \mathrm{~s}, 100$ $\mu$ s duration) using a Master-8 stimulator (A.M.P.I.). Stimulus shock intensity was increased gradually until a fixed-latency EPSC was evoked consistently at a minimum intensity. The latency was measured from the stimulus shock to the onset of the first EPSC evoked in each burst, and the jitter was then calculated as SD of the latency and averaged across $\geq 30$ ST shocks. These low-jitter $(<200 \mu \mathrm{s})$, consistent-waveform EPSCs were selected for study as a monosynaptic unitary ST afferent input (Doyle and Andresen, 2001; Bailey et al., 2006a). Capsaicin (CAP; 100 nM) tests were conducted at the end of each experiment to verify vanilloidsensitive $\left(\mathrm{TRPV}^{+}{ }^{+}\right.$) or vanilloid-insensitive $\left(\mathrm{TRPV}^{-}{ }^{-}\right.$) afferents (Doyle and Andresen, 2001; Bailey et al., 2006a; Peters et al., 2010).

ST-eEPSC and sEPSC analyses. Evoked EPSCs (ST-eEPSCs) were examined for $>20$ successive trials $(2 \mathrm{~min})$ to bursts of five ST shocks delivered every $6 \mathrm{~s}$, and the mean peak amplitude was measured (generally the first response, EPSC1). From each stimulus trial, the basal activity was measured as the number of sEPSCs occurring in the $1 \mathrm{~s}$ preceding ST activation and collected across trials. Thus, ST-eEPSCs and sEPSCs were assessed at the same time in each cell. Designation of $\mathrm{CB}_{1}{ }^{+}$ST-eEPSCs required that significant decreases of EPSC1 amplitude occurred within individual experiments (20 trials each) to $7 \mathrm{~min}$ application of ACEA (10 $\mu \mathrm{M})$, WIN $(10 \mu \mathrm{M})$, or NADA $(5-10 \mu \mathrm{M})$. For statistical comparisons, values were tested for normal distributions, and appropriate parametric or nonparametric statistics were used, including Kolmogorov-Smirnov (KS) tests of interevent intervals and sEPSC amplitudes, $t$ tests (twogroup comparisons) or one/two-way repeated-measures (RM) ANOVA with post hoc comparisons (generally Tukey's) for more than two groups.

Thermally evoked sEPSCs. Bath temperature was controlled within $1^{\circ} \mathrm{C}$ using the inline heating system. Previous experiments indicate that ST afferents associated with substantial asynchronous EPSCs are indicative of TRPV1 expression (Peters et al., 2010), and we incorporated thermal tests in selected experiments when TRPV1 was present. In these protocols, ST-eEPSCs were measured initially at $32^{\circ} \mathrm{C}$. For thermal tests, sEPSC activity was recorded during slow ramp increases in bath temperature to $36^{\circ} \mathrm{C}$, followed by a slow ramp return to $32^{\circ} \mathrm{C}$. The rate of temperature change was kept to $4^{\circ} \mathrm{C}$ for $3 \mathrm{~min}$ to evoke reproducible steady-state sEPSC rates. The sEPSC responses to the ramp increases and decreases in temperature were analyzed separately. Bath temperature values and sEPSC rates were averaged across the same $10 \mathrm{~s}$ intervals (Clampfit; Molecular Devices). Arrhenius relations were calculated as plots of the log of the event frequency versus the temperature [1000/T $\left.\left({ }^{\circ} \mathrm{K}\right)\right]$, and this relation was fitted by linear regression with the slope as a measure of the thermal sensitivity. All thermally responsive neurons responded to CAP and were thus TRPV $1^{+}$. The sEPSCs were collected and analyzed in $10 \mathrm{~s}$ bins using MiniAnalysis (Synaptosoft) with synaptic events $>10 \mathrm{pA}$ detected. To test for $\mathrm{CB}_{1}$ actions, ST-evoked and thermal responses were recorded before and during the application of $10 \mu \mathrm{M}$ ACEA, $10 \mu \mathrm{M}$ WIN, or 5-10 $\mu \mathrm{M}$ NADA as an RM design. The $\mathrm{CB}_{1}$ antagonist/ inverse agonist AM251 [N-1-(2,4-dichlorophenyl)-5-(4-iodophenyl)-4methyl- $N$-1-piperidinyl- $1 \mathrm{H}$-pyrazole-3-carboxamide; $10 \mu \mathrm{M}$ (Pertwee et al., 2010)] was tested against the agonist in selected experiments. Thermal responses were not assayed in neurons receiving TRPV1 ${ }^{-}$ST afferents, because previous tests established their very low thermally sensitivity (Peters et al., 2010; Shoudai et al., 2010). In some experiments, miniature EPSCs (mEPSCs) were measured in the presence of $1 \mu \mathrm{M}$ TTX.

\section{Results}

$\mathrm{CB}_{1}$ activation depresses evoked release regardless of TRPV1 ST shocks evoked fixed-latency, monosynaptic eEPSCs in horizontal brainstem slices that were similar for neurons receiving $\mathrm{TRPV}^{+}{ }^{+}$or TRPV ${ }^{-}$afferents (ST-eEPSCs; Fig. 1; Andresen et al., 2012). The TRPV1 agonist CAP (100 nM) identified TRPV ${ }^{+}$ afferents (Fig. 1C) by blocking evoked transmission but did not 


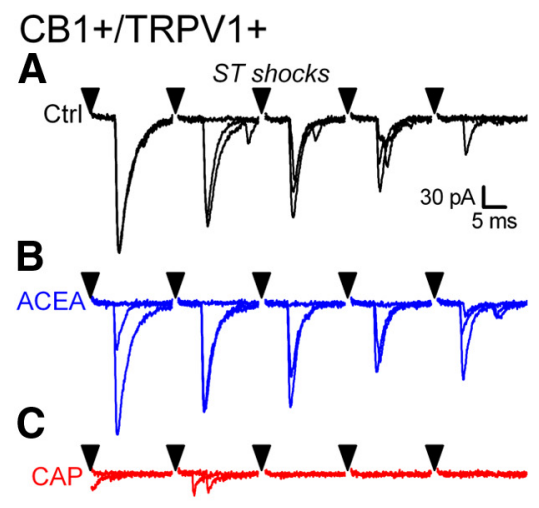

CB1+/TRPV1-

$\mathbf{F}$

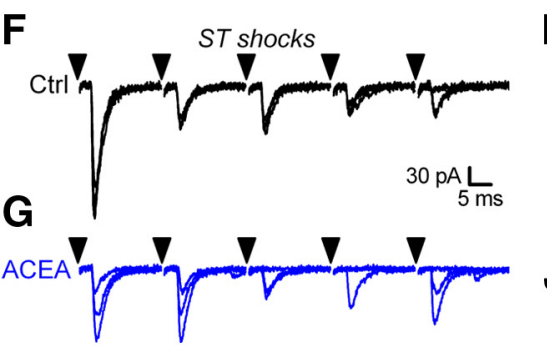

H

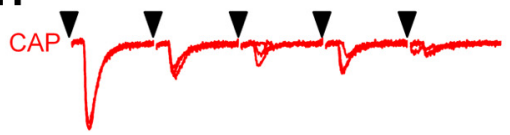

D
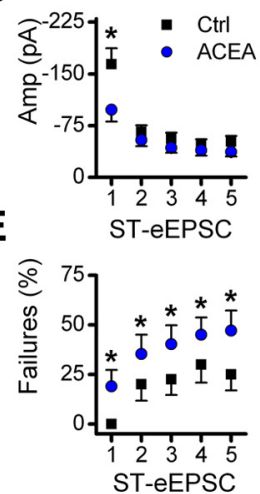

I
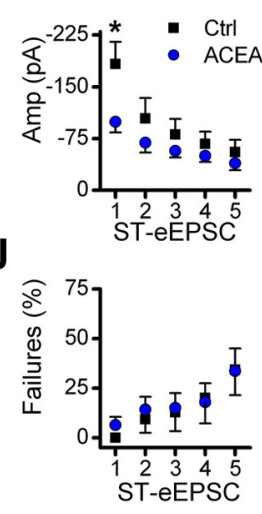

Figure 1. ACEA equally depressed evoked glutamate release (eEPSCS) from TRPV1 ${ }^{+} / \mathrm{CB}_{1}{ }^{+}$ and TRPV $1-/ \mathrm{CB}_{1}{ }^{+}$afferents. Bursts of five ST shocks (arrowheads) activated synchronous ST-eEPSCs that had similar amplitudes and frequency-dependent depression between afferent types. Representative current traces are overlaid from three trials. $\boldsymbol{A}$, In a TRPV $1^{+}$afferent, ST shocks always evoked a synchronous EPSC on the first stimulus in control (ctrl, black), and subsequent shocks evoked either a smaller-amplitude EPSC (i.e., frequency-dependent depression) or a failure (no synchronous EPSC). $\boldsymbol{B}$, ACEA (10 $\mu \mathrm{m}$, blue) reduced the amplitude of ST-eEPSC1, increased its amplitude variance, and caused failed ST-eEPSCS. C, CAP (red, $100 \mathrm{~nm}$ ) blocked all ST-eEPSCs and confirmed the afferent as TRPV $1{ }^{+}$. D, Across TRPV $1{ }^{+}$afferents $(n=$ 14), ACEA reduced ST-eEPSC 1 from control ( ${ }^{*} p<0.01$, two-way RM-ANOVA) with no effect on ST-eEPSC2-eEPSC5 ( $p>0.1$ in all cases, two-way RM-ANOVA). Frequency-dependent depression of ST-eEPSCs remained substantial after ACEA ( $p<0.001$, two-way RM-ANOVA). $E$, ACEA increased ST-eEPSC failures across $\mathrm{CB}_{1}{ }^{+} /$TRPV $1^{+}$afferents $\left({ }^{*} p<0.05\right.$, two-way RM-ANOVA). Thus, $\mathrm{CB}_{1}$ activation has two distinct presynaptic actions on evoked glutamate release from $\mathrm{CB}_{1}{ }^{+} / \mathrm{TRPV}_{1}{ }^{+}$afferents: depression of ST-eEPSC1 and increased synaptic failures. $\boldsymbol{F}$, In a TRPV1 ${ }^{-}$afferent, the pattern of synchronous ST-eEPSCs was indistinguishable from TRPV1 ${ }^{+}$ afferents $(\boldsymbol{A})$. G, ACEA similarly decreased ST-eEPSC amplitudes and increased the amplitude variance while enhancing synaptic failures. $\boldsymbol{H}$, The failure of CAP (red, $100 \mathrm{~nm}$ ) to block STeEPSCs identified this neuron as only receiving TRPV1 ${ }^{-}$ST afferents. $I, 0$ naverage $(n=7), C_{1}$ activation significantly reduced ST-eEPSC1 amplitude $\left({ }^{*} p=0.01\right.$, two-way RM-ANOVA), whereas ST-eEPSC2-eEPSC5 were unaffected ( $p>0.1$ in all cases, two-way RM-ANOVA). Frequency-dependent depression of evoked EPSCs remained substantial after ACEA ( $p<$ 0.001 , two-way RM-ANOVA). J, Across this cohort of cells $(n=7)$, ACEA did not increase failures $(p=0.5$, two-way RM-ANOVA).

alter TRPV1 ${ }^{-}$ST-eEPSCs (Fig. $1 H$ ). Activation of $\mathrm{CB}_{1}$ with the selective agonist ACEA significantly depressed ST-eEPSC1 amplitude from most NTS afferents $\left(\mathrm{CB}_{1}{ }^{+}, 63 \%\right.$ control), regardless of whether they were TRPV ${ }^{+}$(14 of 18$)$ or $\mathrm{TRPV}^{-}$(7 of 9) (Fig. 1). In TRPV $1^{+}$afferents, $\mathrm{CB}_{1}$ activation also increased evoked synaptic failures from 0 to nearly $25 \%$ for EPSC1, and the subsequent shocks within the train of five failed at similarly high rates (Fig. $1 B, E$ ). However, in TRPV1 ${ }^{-}$neurons, the ST-eEPSC failure rate was unchanged by $\mathrm{CB}_{1}$ activation (Fig. $1 G, J$ ). ACEA

CB1+/TRPV1-

A

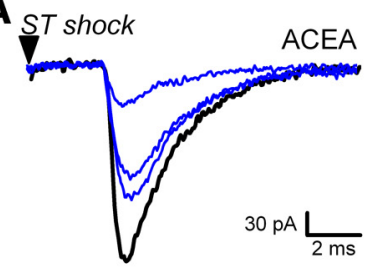

B
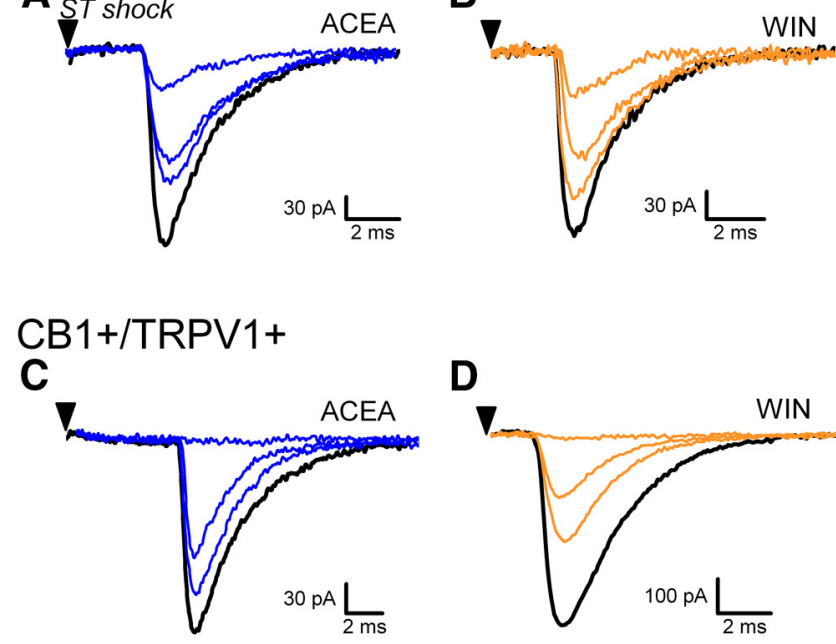

$\mathbf{E}$

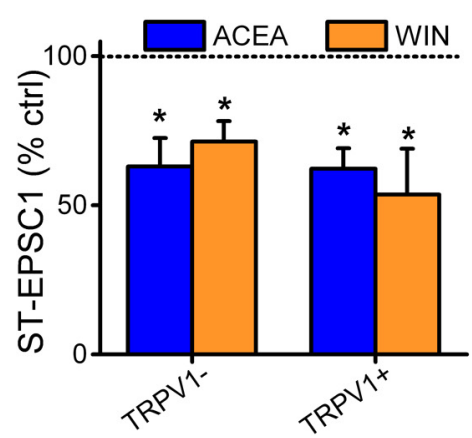

Figure 2. $\quad \mathrm{CB}_{1}$ activation equally depressed action potential-evoked glutamate release (STeEPS(s). Low-intensity ST shocks (arrowheads) activated single ST afferents to generate consistent-amplitude eEPSCs [for clarity, 1 representative trace in ctrl (black) is overlaid with 3 trials in ACEA or WIN]. Separate methods established that neurons received TRPV $1^{+}$afferents or not (see Materials and Methods). Some afferents expressed only $\mathrm{CB}_{1}\left(\mathrm{CB}_{1}{ }^{+} / \mathrm{TRPV}^{-}{ }^{-}\right)$and ACEA (10 $\mu \mathrm{m}$, blue, $\boldsymbol{A})$ or WIN 55,212-2 (10 $\mu \mathrm{m}$, orange, $\boldsymbol{B})$ reduced ST-eEPSC amplitudes. $\mathrm{CB}_{1}{ }^{+} / \mathrm{TRPV} 1^{+}$afferents responded similarly $(\boldsymbol{C}, \boldsymbol{D}) . \boldsymbol{E}, \mathrm{CB}_{1}$ activation depressed ST-eEPSCS from TRPV1 ${ }^{+}$(ACEA, ${ }^{*} p=0.001, n=14 ;$ WIN $^{*}{ }^{*} p=0.03, n=5$, paired $t$ tests) or TRPV1 ${ }^{-}$ (ACEA, ${ }^{*} p=0.047, n=7 ; \mathrm{WIN}^{*}{ }^{*} p=0.02, n=5$, paired $t$ tests) afferents regardless of agonist or afferent type ( $p=0.9$, one-way ANOVA).

and WIN produced similar amplitude and failure actions as $\mathrm{CB}_{1}$ agonists (Fig. 2). The $\mathrm{CB}_{1}$ antagonist/inverse agonist AM251 had no effect alone ( $98 \pm 2 \%$ control, $p=0.3$, paired $t$ test, $n=3$ ) but blocked ACEA actions on ST-eEPSCs from both afferent subtypes (TRPV $1^{-}, 101 \pm 7 \%$ control, $p=0.6, n=3$; TRPV $1^{+}$, $88 \pm 5 \%$ control, $p=0.2, n=5$, two-way RM-ANOVA). As predicted from variance-mean analysis of ST glutamate release from this high release probability synapse (Bailey et al., 2006b; Andresen and Peters, 2008; Peters et al., 2008), the variance of ST-eEPSC1 amplitudes increased substantially as the mean amplitude declined (TRPV1 ${ }^{+}, 539 \pm 150 \%$ control, $p<0.001$; $\mathrm{TRPV}^{-}{ }^{-}, 204 \pm 25 \%$ control, $\left.p=0.04\right)$. Together, these observations suggest that $\mathrm{CB}_{1}$ activation decreased the evoked release probability regardless of TRPV1 subtype.

Basal glutamate release is unaffected by $\mathrm{CB}_{1}$ receptors Although $\mathrm{CB}_{1}$ activation markedly depressed ST-eEPSCs, careful scrutiny of the sEPSC activity preceding ST stimulation from the same afferents suggested that spontaneous glutamate release was unaltered by $\mathrm{CB}_{1}$. All NTS afferents had ongoing basal sEPSC 

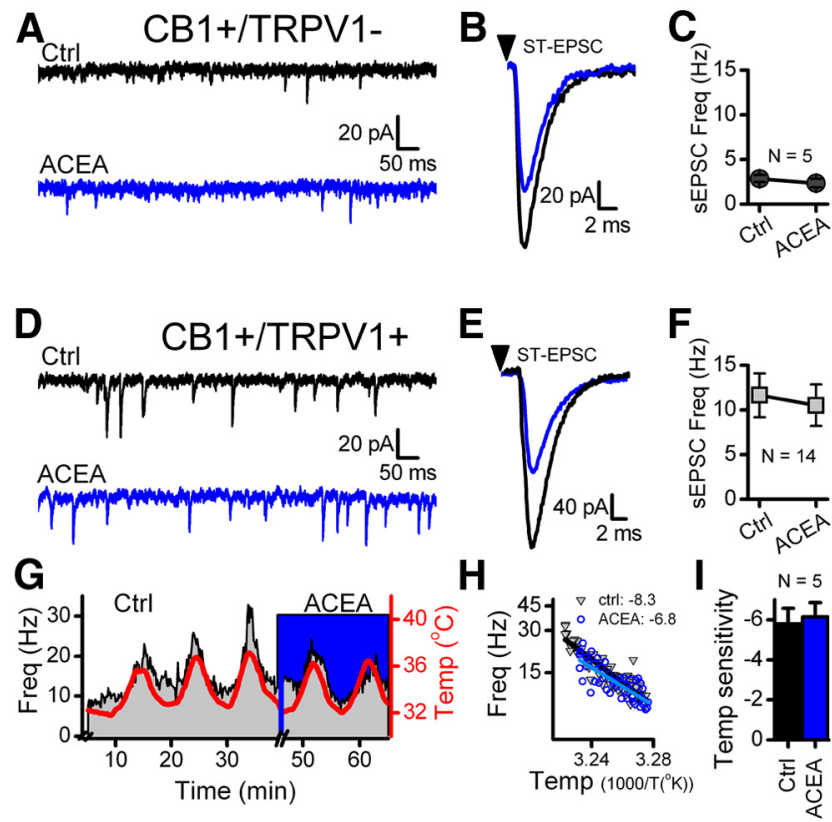

Figure 3. $C B_{1}$ activation failed to alter $S E P S C$ despite depression of eEPSCs from the same afferent. In TRPV1 ${ }^{-}(\boldsymbol{A}-\boldsymbol{C})$ or TRPV1 ${ }^{+}(\boldsymbol{D}-\boldsymbol{I})$ ST afferents, ACEA (10 $\mu \mathrm{m}$, blue) did not alter basal sEPSC rates $(\boldsymbol{A}, \boldsymbol{D})$ but reduced ST-eEPSCS $(\boldsymbol{B}, \boldsymbol{E})$ from control (Ctrl, black). Across afferents, ACEA did not affect basal sEPSC frequency $(\boldsymbol{C}, p=0.2$, paired $t$ test) or amplitude $(p=0.3$, paired $t$ test) from TRPV1 ${ }^{-}$or TRPV1 ${ }^{+}$( $F$; frequency, $p=0.1$; amplitude, $p=0.6$, paired $t$ tests) afferents. Note the substantially higher SEPSC rates characteristic of TRPV ${ }^{+}$compared with TRPV1 ${ }^{-}$( $p=0.01, t$ test). G, sEPSC frequency (10 s bins black/filled gray) from TRPV1 ${ }^{+}$ afferents tracked changes in bath temperature (red), but ACEA (blue box) had no effect. $x$-Axis breaks mark ST-eEPSC measurements. $\boldsymbol{H}$, Temperature sensitivity was determined by linear regression fits of the log sEPSC frequency versus temperature [1000/T ( $\left.\left.{ }^{\circ} \mathrm{K}\right)\right]$ from increasing temperature ramps in control (black inverted triangles) and ACEA (blue circles). $I$, Across neurons, temperature sensitivities were unaltered by $\mathrm{CB}_{1}$ activation ( $p=0.8$, paired $t$ test).

activity, and activation of $\mathrm{CB}_{1}$ with ACEA remarkably failed to alter these rates (Fig. $3 A, D$ ). So despite substantial inhibition of evoked release from $\mathrm{CB}_{1}{ }^{+}$ST afferents (Fig. $3 B, E$ ), sEPSC rates from either afferent class were unaffected (Fig. $3 C, F$ ). Similarly, WIN reduced ST-eEPSC amplitudes without altering sEPSCs rates or amplitudes from either TRPV1 type (all $p$ values $>0.2$, paired $t$ tests). AM251 alone did not alter basal TRPV ${ }^{+}$sEPSCs rates $(p=0.9$, paired $t$ test). Furthermore, in the absence of action potentials (in TTX), neither mEPSC frequencies ( $p=0.5$, $n=4$, paired $t$ test) nor amplitudes ( $p=0.2$, paired $t$ test) from TRPV $1^{+}$afferents were inhibited by $\mathrm{CB}_{1}$ activation (additional data not shown). Despite the inhibition of evoked glutamate release (i.e., ST-eEPSCs), the ongoing basal glutamate release (i.e., sEPSCs) was not altered from the same afferents. These observations suggest that $\mathrm{CB}_{1}$ discretely regulates evoked glutamate release without disturbing the spontaneous release process.

\section{$\mathrm{CB}_{1}$ fails to alter thermal regulation of sEPSCs}

Under baseline conditions, spontaneous glutamate release is substantially higher from TRPV1 ${ }^{+} \mathrm{ST}$ afferents (Shoudai et al., 2010). Although this might suggest that the high release rate is a passive process, cooling below physiological temperatures substantially reduces the sEPSC rate only in TRPV $1^{+}$ neurons and indicates an active role for thermal transduction in TRPV ${ }^{+}$terminals (Shoudai et al., 2010). To test whether $\mathrm{CB}_{1}$ activation modified this active thermal release process, we compared the sEPSC rate changes to thermal challenges. In $\mathrm{CB}_{1}{ }^{+} \mathrm{TRPV}^{+}{ }^{+}$afferents (Fig. $3 B, E$ ), small changes in bath

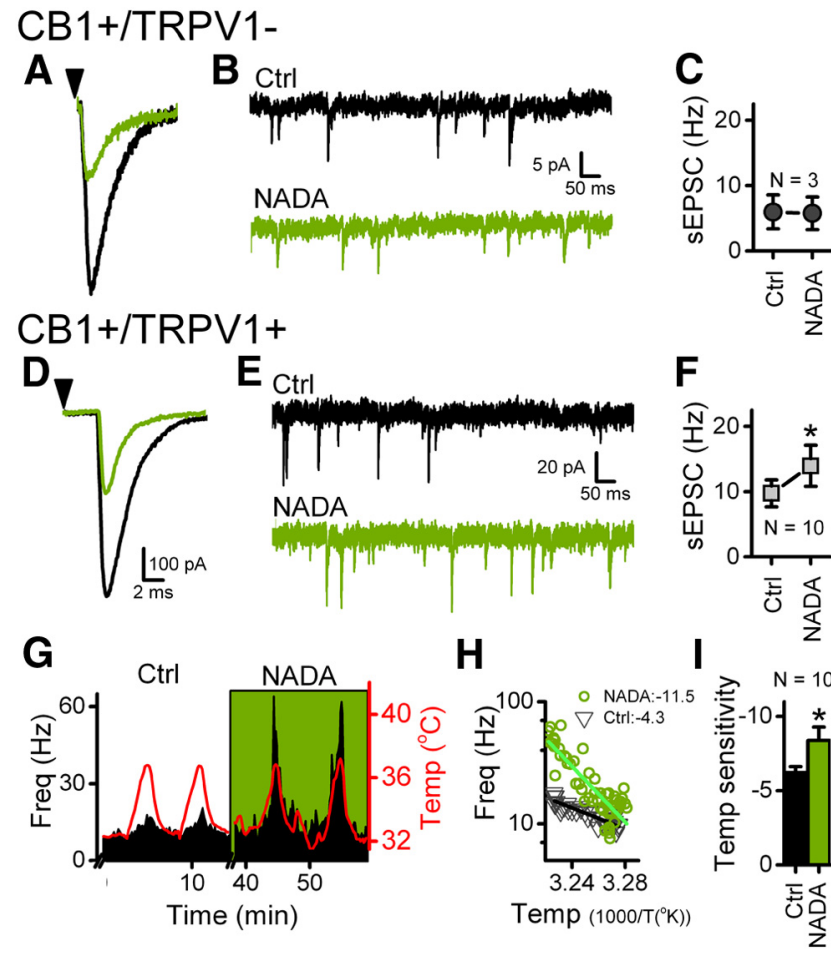

Figure 4. NADA activated both $C_{1}$ and TRPV1 with opposite effects on glutamate release NADA (5 $\mu \mathrm{m}$, green) inhibited ST-eEPSCs whether TRPV1 was present $(\boldsymbol{D})$ or not $(\boldsymbol{A})$. Across neurons receiving TRPV ${ }^{+}$afferents $(n=10)$, NADA $(5-10 \mu \mathrm{m})$ reduced ST-eEPSC 1 by $34 \pm$ $4 \%$ ( ${ }^{*} p<0.01$, two-way RM-ANOVA) without affecting ST-eEPSC2-eEPSC5 ( $p>0.2$, twoway RM-ANOVA). NADA (5-10 $\mu \mathrm{m})$ similarly reduced synchronous release from TRPV1 ${ }^{-}$afferents $(n=4)$, both ST-eEPSC1 ( $33 \pm 6 \%, p<0.0001$, two-way RM-ANOVA) and ST-eEPSC $(27 \pm 12 \%, p<0.01$, two-way RM-ANOVA). However, NADA increased basal sEPSC rates only from TRPV $1{ }^{+}$afferents $\left(\boldsymbol{B}, \boldsymbol{C} ; \mathrm{TRPV}{ }^{+}{ }^{+}{ }^{*} p=0.02 ; \boldsymbol{E}, \boldsymbol{F}, \mathrm{TRPV}{ }^{-}, p=0.3\right.$, paired $t$ tests), indicating a functionally independent effect of $C_{1}$-induced depression of eEPSCs versus the enhanced sEPSC release mediated by TRPV1. NADA (5-10 $\mu \mathrm{m})$ also facilitated thermal sensitivity from TRPV1 ${ }^{+}$afferents $(\boldsymbol{G}-\boldsymbol{I}) . \mathbf{G}$, Bath temperature (red) and sEPSCs (black) were binned $(10 \mathrm{~s})$, and the sensitivity $(\boldsymbol{H})$ was determined as described in Figure $3 H$. The sensitivities were averaged across neurons $\left(\boldsymbol{I} ;{ }^{*} p=0.03\right.$, paired $t$ test). Ctrl, Control.

temperature modified the sEPSC rate (Fig. $3 G$ ), and the average $(n=5)$ thermal sensitivity relationship for sEPSC rates was unaffected by ACEA (Fig. $3 H, I$ ). The lack of effect of $\mathrm{CB}_{1}$ activation on thermally regulated spontaneous glutamate release-despite effectively depressing action potential-evoked glutamate release-suggests that the second-messenger cascade activated by $\mathrm{CB}_{1}$ failed to alter spontaneous release or its modulation by temperature.

\section{NADA oppositely modulates evoked and TRPV1-operated} glutamate release

Endocannabinoids and endovanilloids share similar structural motifs (Di Marzo et al., 1998), and some arachidonate derivatives, including NADA, activate both $\mathrm{CB}_{1}$ and TRPV1 (Marinelli et al., 2003, 2007; Matta and Ahern, 2011). As expected, NADA depressed ST-eEPSC amplitudes for $\mathrm{CB}_{1}{ }^{+}$ST afferents similarly whether they were TRPV ${ }^{+}{ }^{+}$or TRPV1 ${ }^{-}$(Fig. $4 A, D$ ). Although NADA did not alter the rate of ST-evoked failures from TRPV ${ }^{+}$ ( $p=0.08$, two-way RM-ANOVA $)$ or TRPV ${ }^{-}(p=0.4$, two-way RM-ANOVA) afferents, it effectively mimicked $\mathrm{CB}_{1}$-selective agents to depress action potential-evoked release of glutamate. NADA simultaneously increased ongoing basal release rates only from afferents with TRPV1 ${ }^{+}$(Fig. $4 E, F$ ) but not from TRPV1 ST afferents (Fig. $4 B, C$ ). In addition, NADA facilitated thermally 

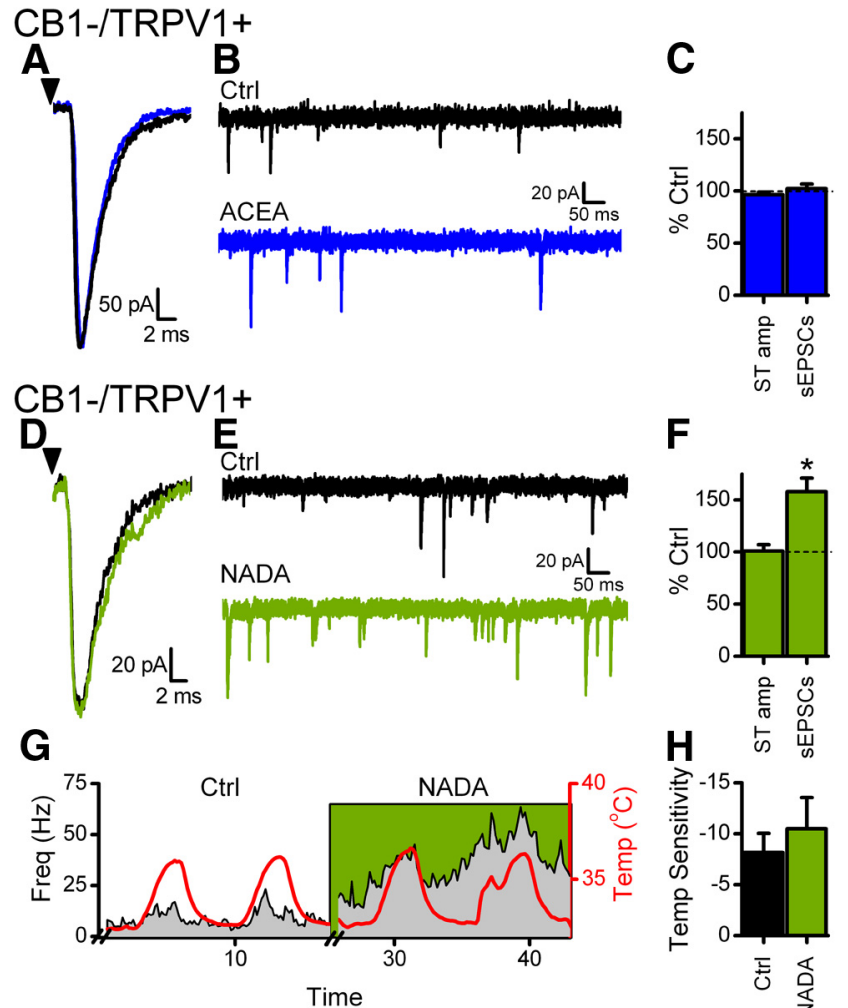

$\mathbf{F}$
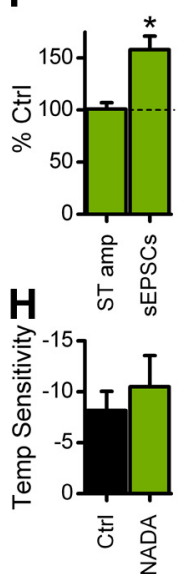

Figure 5. Afferents lacking $C_{1}$ receptors served as a natural control for NADA actions. Representative current traces are from second-order NTS neurons that received only TRPV1 ${ }^{+}$afferent(s). $A$, ST shocks evoked ST-eEPSCs from this TRPV ${ }^{+}$afferent that were unaltered by ACEA (10 $\mu \mathrm{m}$, blue; $p=0.9$, paired $t$ test) identifying the afferent as $\mathrm{CB}_{1}{ }^{-}$. $\boldsymbol{B}$, The sEPSC rates from the same afferent (ctrl, black) were unaffected by $A C E A$ (blue; $p=0.8, \mathrm{KS}$ test). $C$, Across $\mathrm{CB}_{1}{ }^{-}$afferents $(n=5)$, neither the ST-eEPSC amplitude ( $p=0.6$, paired $t$ test) nor the frequency of $\operatorname{SEPSCS}$ ( $p=0.9$, paired $t$ test) were affected by $\mathrm{CB}_{1}$-specific activation by ACEA. $D$, Similarly, a different second-order neuron with TRPV ${ }^{+}$afferents had no ST-eEPSC response to NADA (green, $5 \mu \mathrm{m} ; p=0.3$, paired $t$ test) and was thus void of $C_{1}$. $E$, Nonetheless, NADA nearly doubled the rate of $\operatorname{SEPSCS}\left(p=0.001, \mathrm{KS}\right.$ test). $\boldsymbol{F}$, Across $\mathrm{CB}_{1}{ }^{-}$afferents tested with $\operatorname{NADA}(n=4)$, the ST-eEPSC amplitude was unaffected by NADA ( $p=0.9$, paired $t$ test) but showed increased $s E P S C$ rates $\left({ }^{*} p=0.04\right.$, paired $t$ test). G, NADA enhanced the sEPSC frequency (10 s bins black/filled gray) response to increases in bath temperature (red). $x$-Axis breaks mark ST-eEPSC measurements. $\boldsymbol{H}$, Across afferents, NADA increased temperature sensitivity by $30 \%$. These results suggest that NADA acts on SEPSC regulation through TRPV1 regardless of $\mathrm{CB}_{1}$ expression.

triggered sEPSCs rates in neurons receiving TRPV $1{ }^{+} \mathrm{ST}$ afferents (Fig. 4G-I). TRPV ${ }^{+}$afferents that lacked suppression of STeEPSCs in response to $\mathrm{CB}_{1}$ agonist $\left(\mathrm{CB}_{1}{ }^{-}\right)$served as naturally occurring "controls" for $\mathrm{CB}_{1}$ actions (Fig. 5). NADA only enhanced basal and thermally triggered sEPSCs without altering ST-eEPSC amplitudes from these $\mathrm{CB}_{1}{ }^{-} / \mathrm{TRPV} 1^{+}$afferents, which is consistent with endocannabinoid actions solely at TRPV1.

In afferents with both receptors $\left(\mathrm{CB}_{1}{ }^{+} / \mathrm{TRPV} 1^{+}\right.$; Fig. 6), the TRPV1 antagonist capsazepine blocked sEPSC enhancement by NADA but did not prevent the ST-eEPSC depression (Fig. 6A$D)$. Likewise, the TRPV1 antagonist 5'-iodoresiniferatoxin (iRTX) blocked NADA-mediated increases in sEPSCs (control, $16.0 \pm 4.6 \mathrm{~Hz}$ vs NADA + iRTX, $14.9 \pm 5.0 \mathrm{~Hz} ; n=5, p=0.6$, one-way RM-ANOVA). These actions of TRPV1 antagonists indicate that NADA acted on spontaneous release by binding to the vanilloid binding site on TRPV1 receptors. Conversely, AM251 blunted NADA-induced inhibition of the ST-eEPSC but failed to prevent NADA from increasing the sEPSC rate (Fig. $6 E-H)$. This
CB1+/TRPV1+
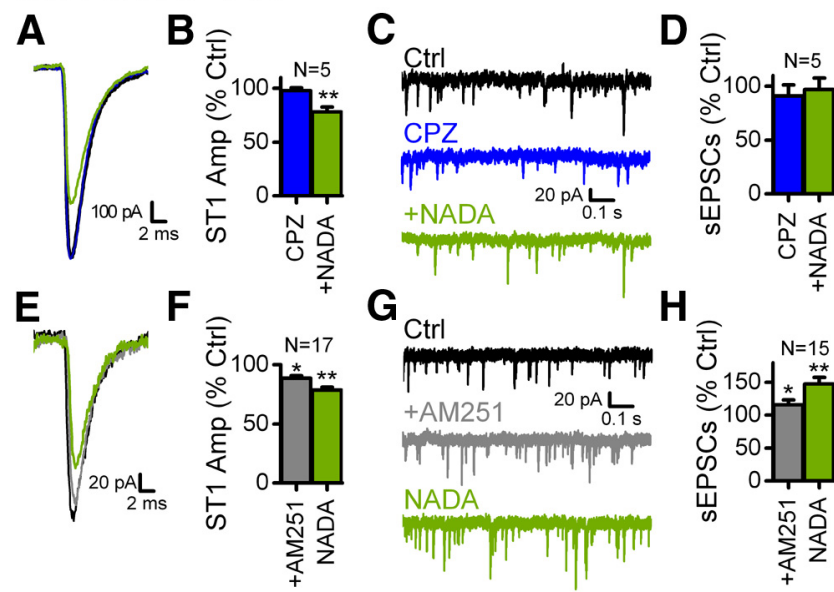

Figure 6. Antagonists for TRPV1 [capsazepine (CPZ), blue] and $C_{1}$ ( $A M 251$, gray) selectively blocked the NADA-induced effects associated with each respective receptor. $A$, Representative traces from a TRPV1 ${ }^{+}$afferent demonstrates that $10 \mu \mathrm{M}$ CPZ (blue) did not block the NADAinduced reduction (green) in ST-eEPSC amplitude compared with control (Ctrl, black). This demonstrates the lack of direct action of TRPV1 on action potential-evoked glutamate release and reinforces the role of $C B_{1}$ receptors in reducing ST-eEPSC amplitude. $B$, Across neurons, $C P Z$ had no effect alone and did not block NADA-induced reduction of ST-eEPSC1 ( ${ }^{* *} p=0.02$, one-way RM-ANOVA). $\boldsymbol{C}$, In contrast to eEPSCS, sEPSC traces from the same NTS neuron as $\boldsymbol{A}$ demonstrated that CPZ blocked the increase induced by NADA, suggesting action via TRPV1. $D$, Across neurons, CPZ had no effect on sEPSCs and prevented NADA enhancement ( $p=0.5$, one-way RM-ANOVA). $\boldsymbol{E}$, Traces from a different TRPV1 ${ }^{+}$ST afferent demonstrate that AM251 $(20 \mu \mathrm{m})$ blunts the effect of NADA (10 $\mu \mathrm{m}$, green) on ST-eEPSC1 (ST1). F, Across afferents, NADA $\left(5-10 \mu \mathrm{M}\right.$ ) reduced the amplitude of ST-eEPSC 1 by $22 \%$ ( ${ }^{* *} p<0.05$, two-way RM-ANOVA), but when it was coapplied with AM251 $(10-20 \mu \mathrm{M})$, there was only an $11 \%$ reduction $\left({ }^{*} p<\right.$ 0.05 , two-way RM-ANOVA). This demonstrates that NADA reduced evoked glutamate via $C_{1}$. $\boldsymbol{G}$, Traces from the same NTS neuron as $\boldsymbol{E}$ demonstrate that this $C_{1}$ antagonist did not block NADA-induced increases in sEPSC rates. $\boldsymbol{H}$, Across afferents, NADA increased sEPSC rates $\left({ }^{* *} p<\right.$ 0.001 , two-way RM-ANOVA) regardless of AM251 (* $p=0.01$, two-way RM-ANOVA), supporting previous observations that NADA increases sEPSCs via TRPV1.

result suggests that NADA acts on evoked release by activating the $\mathrm{CB}_{1}$ receptor. Thus, NADA has dual opposing actions on glutamate release within single afferents attributed separately to $C_{1}$ and TRPV1 activations. The independence and selectivity of the actions suggests that $\mathrm{CB}_{1}$ and TRPV1 signaling function without crosstalk between the two mechanisms (De Petrocellis et al., 2001; Evans et al., 2007). Such findings are consistent with complete functional isolation of $\mathrm{CB}_{1}$ and its second-messenger system from TRPV1-mediated responses.

\section{Discussion}

In this study, we demonstrate that $\mathrm{CB}_{1}$ and TRPV1 separately targeted different forms of glutamate release from ST primary afferent terminals. $\mathrm{CB}_{1}$ activation inhibited evoked neurotransmission, and its actions were limited to aspects of action potential-evoked release (decreases in ST-eEPSC amplitude and increases in failure rates) without disturbing spontaneous vesicular release (including the TRPV1-operated form) from the same afferents. Although central terminals within the NTS express VACCs and may additionally express TRPV1 (Mendelowitz et al., 1995; Andresen et al., 2012), the actions of $\mathrm{CB}_{1}$-selective agents were consistent across multiple subsets of $\mathrm{CB}_{1}{ }^{+}$afferents regardless of TRPV1 expression. In contrast, the endocannabinoid NADA triggered both inhibitory $\mathrm{CB}_{1}$ actions on evoked release but also augmented spontaneous and thermal release of glutamate (sEPSCs) by activating TRPV1. We found no evidence that the pronounced 
$\mathrm{CB}_{1}$ action on the evoked release process affected spontaneous and TRPV1-mediated glutamate release and vice versa. Despite being a GPCR with intracellular second messengers, $\mathrm{CB}_{1}$ discretely targeted evoked glutamate release without actions on spontaneous release. These data are consistent with two noncompeting pools of vesicles within ST cranial afferent terminals that can be independently modulated.

Our study focused on ST transmission of cranial visceral afferents arising from two afferent phenotypes based on differences in TRPV1 expression. Both myelinated (TRPV1 ${ }^{-}$) and unmyelinated $\left(\mathrm{TRPV} 1^{+}\right)$primary visceral afferents use similar mechanisms for evoked release that generate a characteristically strong frequency-dependent depression of ST transmission (Bailey et al., 2006b; Andresen and Peters, 2008; Peters et al., 2008). Several GPCRs modulate evoked ST-eEPSCs regardless of TRPV1 status (Appleyard et al., 2005; Bailey et al., 2006b; Peters et al., 2008; Fawley et al., 2011). In the present studies, three different $\mathrm{CB}_{1}$ agonists-ACEA, WIN, and NADA—similarly depressed STeEPSCs regardless of TRPV1 status, and the $\mathrm{CB}_{1}$-selective antagonist/inverse agonist AM251 blocked these actions. AM251 showed no effects when administered alone in NTS slices, a finding that rules out tonic excitatory actions reported in some sensory neurons (Patil et al., 2011). $\mathrm{CB}_{1}$ activation attenuated eEPSCs from most ST afferents, suggesting a similar widespread presynaptic $\mathrm{CB}_{1}$ expression among ST afferents. These $\mathrm{CB}_{1}$ actions on evoked release likely arise from inhibition of VACCs in ST axons directly linked to highly synchronous release (Mendelowitz et al., 1995; Brown et al., 2004; Castillo et al., 2012).

ST-evoked transmission relies on EPSCs recruited at minimal stimulus strength with latency and amplitude characteristics consistent with responses evoked by a single axon (Doyle and Andresen, 2001; McDougall et al., 2009). Detailed studies have indicated that, in basal conditions, ST-eEPSCs average a $90 \%$ probability of glutamate release from the readily releasable pool of vesicles regardless of TRPV1 expression (Bailey et al., 2006b). The uncommonly high release probabilities of ST afferents likely contribute to the near zero failure rates for the first shock (McDougall et al., 2009; McDougall and Andresen, 2013). The $\mathrm{CB}_{1}$ mediated depression of the release probability likely reflects actions within the synaptic terminal and was most evident in the $\mathrm{CB}_{1}$-induced increase in ST-eEPSC1 amplitude variance. This $\mathrm{CB}_{1}$ effect follows from the steep parabolic relation between variance and amplitude for this high release synapse (Bailey et al., $2006 \mathrm{~b}$ ). The lack of $\mathrm{CB}_{1}$ effects on consequent ST-eEPSCs (STeEPSC2-eEPSC5) likely reflects a mixing of these two mechanisms in which a $\mathrm{CB}_{1}$-mediated decrease in release probability attenuates vesicle depletion and consequently means that more vesicles are available for release on the second shock. A lower probability of release combined with less frequency-dependent depression during $\mathrm{CB}_{1}$ activation might result in net responses that were unchanged in both afferent types (Fig. $1 D, I$ ).

$\mathrm{CB}_{1}$ activation interrupted the usually faithful conversion of ST action potentials to eEPSCs by increasing synaptic failures only in TRPV ${ }^{+}$afferents. TRPV1 ${ }^{+}$ST afferents characteristically have much higher use-dependent failure rates compared with TRPV1 ${ }^{-}$afferents (Andresen and Peters, 2008), and this difference between myelinated (TRPV1 ${ }^{-}$) and unmyelinated $\left(\mathrm{TRPV}^{+}{ }^{+}\right.$) primary cranial afferents may reflect critical differences in ion channel expression (Schild et al., 1994; Li et al., 2007). Our observation that transmission along TRPV $1^{-}$afferents was inherently more reliable with lower failures, and an intrinsically higher safety margin may account for the inability of ACEA or WIN to augment failures in TRPV1 ${ }^{-}$ST afferents. GP-

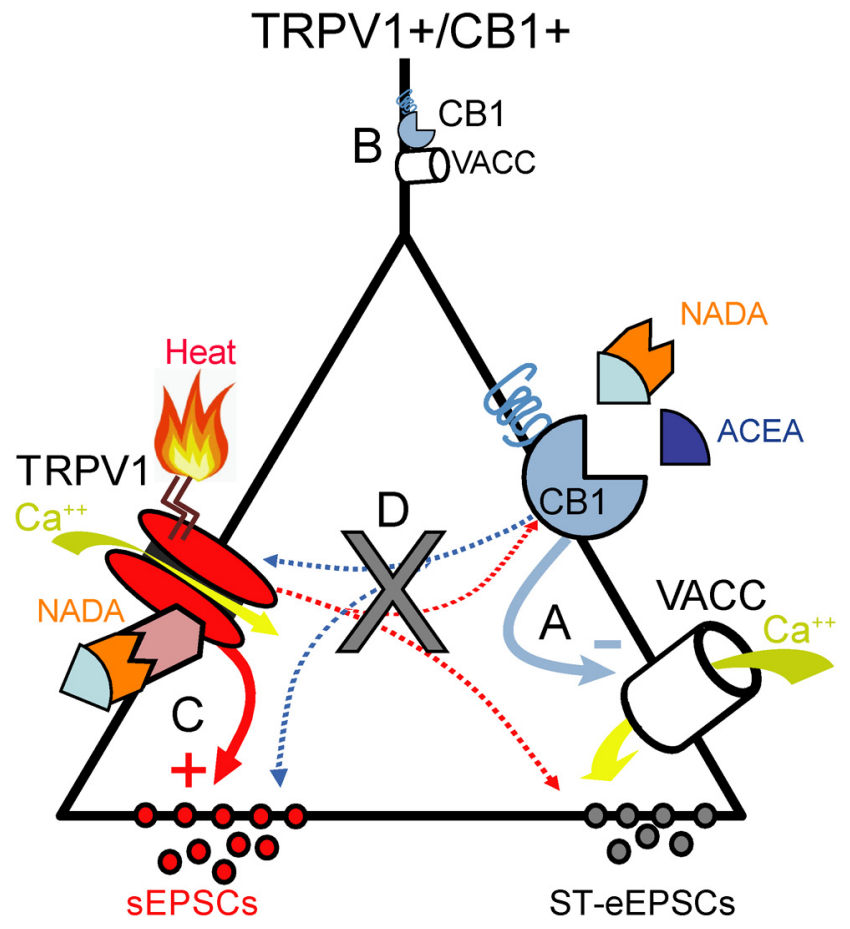

Figure 7. Schematic illustration of $C_{1}$ (blue) and TRPV1 (red) activation to mobilize separate pools of glutamate vesicles. $A$, The $G P C R C B_{1}$ depresses glutamate release from the readily releasable pool of vesicles (gray) measured as ST-eEPSCs. Calcium entry through VACCs primarily regulates this vesicle pool. $C_{1}$ action on ST-eEPSCs is equivocal whether ACEA, WIN (dark blue pie), or NADA (bifunctional agent acting at both $\mathrm{CB}_{1}$ and TRPV1 sites, blue pie/orange key) activates the receptor. $B, C B_{1}$ also interrupts action potential-driven release when activated by ACEA or WIN, likely by blocking conduction to the terminal. C, Calcium sourced from TRPV1 drives spontaneous EPSCs from a separate pool of vesicles (red) on TRPV1 ${ }^{+}$afferents. NADA activates TRPV1, likely through its ligand binding site (pink), to potentiate basal and thermalactivated [heat (flame)] sEPSCs via the temperature sensor (maroon bent hash marks). D, Although the endogenous lipid ligand NADA can activate both $C_{1}$ and TRPV1, selective activation of $C_{1}$ with $A C E A$ or WIN only suppresses voltage-activated glutamate release with no interactions either directly or indirectly with TRPV1. Likewise, TRPV1 activation with NADA does not interact with $\mathrm{CB}_{1}$ or affect ST-eEPSCs, demonstrating that the two pools of glutamate release can be independently regulated.

CRs, including the vasopressin $\mathrm{V}_{1 \mathrm{a}}$ receptor on $\mathrm{ST}$ afferents in the NTS, are found relatively distant from the terminal release sites and affect the failure rate independent of changes in the release probability (Voorn and Buijs, 1983; Bailey et al., 2006b). Thus, $\mathrm{CB}_{1}$-induced increases in conduction failures may well reflect similar conduction failures at relatively remote $\mathrm{CB}_{1}$ receptors (Bailey et al., 2006b; McDougall et al., 2009). The difference we observed in ST-eEPSC failures with activation of $\mathrm{CB}_{1}$ by NADA may relate to the lower affinity of NADA for $\mathrm{CB}_{1}$ compared with the selective agonists tested (Pertwee et al., 2010). Thus, the two actions of $\mathrm{CB}_{1}$ receptor activation are attributed to distinctly separate sites of action: one that decreases release probability (i.e., within the synaptic terminal) and the other affecting conduction (i.e., along the afferent axon) that induces failures of excitation.

A major difference in ST transmission is the presence of TRPV1 in unmyelinated ST afferents (Andresen et al., 2012). In contrast to ST-eEPSCs, elevated basal sEPSCs and thermalmediated release from TRPV ${ }^{+}$afferents are independent of VACCs and instead depend on calcium entry that persists in the presence of broad VACC blockers, such as cadmium (Jin et al., 2004; Shoudai et al., 2010; Fawley et al., 2011). Because sEPSCs depend on external calcium levels (Peters et al., 2010), TRPV1 
appears to provide a second calcium source for synaptic release independent of VACCs (Fig. 7). However, the calcium sourced through TRPV1 does not affect evoked glutamate release. Raising the bath temperature $\left(33-38^{\circ} \mathrm{C}\right)$ strongly activated TRPV1dependent sEPSCs (Shoudai et al., 2010) but not the amplitude of evoked release (Peters et al., 2010). Likewise, when $\mathrm{CB}_{1}$ was absent $\left(\mathrm{CB}_{1}^{-}\right)$or blocked, NADA increased spontaneous and thermal-evoked sEPSCs with no effect on ST-eEPSCs, providing additional evidence that TRPV1-mediated glutamate release is separate from evoked release. The actions of NADA together with temperature are consistent with the polymodal gating of TRPV1 via binding to a separate CAP binding site, as well as temperature actions at a thermal activation site within TRPV1 (Caterina and Julius, 2001). Although other channels may contribute to temperature sensitivity including non-vanilloid TRPs (Caterina, 2007), TRPV1 block with capsazepine or iRTX prevented NADA augmentation of sEPSC responses, indicating a TRPV1-dependent mechanism. Together, our data suggest that presynaptic calcium entry via TRPV1 has access to the vesicles released spontaneously but does not alter release by action potentials and VACC activation (Fig. 7).

Our studies highlight a unique mechanism governing spontaneous release of glutamate from TRPV ${ }^{+}$afferents (Fig. 7). In the NTS, TTX did not alter the rate of sEPSCs activity and demonstrates that very little spontaneous glutamate release originates from distant sources relayed by action potentials (Andresen et al., 2012). Focal activation of afferent axons within $250 \mu \mathrm{m}$ of the cell body generated EPSCs with characteristics indistinguishable from ST-evoked responses in the same neuron (McDougall and Andresen, 2013) and suggests that afferent terminals dominate glutamatergic inputs to second-order neurons, such as the ones in the present study. So although additional, non-afferent glutamate synapses certainly exist on NTS neurons-as evident in polysynaptic-evoked EPSCs that likely represent disynaptic connections (Bailey et al., 2006a) - their contribution to our sEPSC results is likely minor.

Our study adds to emerging data that challenge the conventional view that vesicles destined for action potential-evoked release of neurotransmitter belong to the same pool as those released spontaneously (Sara et al., 2005, 2011; Atasoy et al., 2008; Wasser and Kavalali, 2009; Peters et al., 2010). At synapses with single, common pools of vesicles, depletion by high frequencies of stimulation depressed spontaneous rates (Kaeser and Regehr, 2014). In contrast, the high-frequency bursts of ST activation transiently increased the rate of spontaneous release only from TRPV ${ }^{+}$afferents (Peters et al., 2010). The single pool concept of glutamate release would predict that a singular presynaptic GPCR would modulate all vesicles in the terminal similarly. However, our results clearly indicate that the GPCR $\mathrm{CB}_{1}$ only modulates a subset of glutamate vesicles (eEPSCs). The separation of the mechanisms mediating spontaneous release from action potential-evoked release at ST afferents is consistent with separately sourced pools of vesicles that supply evoked or spontaneous release for cranial visceral afferents.

The discreteness of $\mathrm{CB}_{1}$ from TRPV1 actions in ST transmission was surprising with respect to other primary sensory afferent neurons. The functional isolation and lack of crosstalk between $\mathrm{CB}_{1}$ and TRPV1 when coexpressed in ST afferents suggests quite different compartmentalization than in neurons from the spinal cord dorsal root ganglion and dorsal horn (De Petrocellis et al., 2001; Matta and Ahern, 2011). Because ST-evoked and spontaneous transmissions appear to arise from separate pools, this raises the possibility that the vesicles may be physically separated with different compartmentalization within microdomains or nanodomains, as suggested for VACCs (Bucurenciu et al., 2008; Neher and Sakaba, 2008). Larger-scale separations may occur, such as different boutons for spontaneous and evoked release similar to the neuromuscular junction (Melom et al., 2013; Peled et al., 2014). Little is known about vesicle organization of ST afferent synaptic terminals. The fundamental segregation of the evoked release mechanism from the TRPV1-operated pool indicates that different lipid mediators may adjust ongoing glutamate release for fast synaptic transmission distinct from spontaneous release. Because spontaneously released glutamate is suggested to play a key role in synapse maintenance/ stabilization and tasks such as postsynaptic gene transcription (McKinney et al., 1999; Nelson et al., 2008; Kaeser and Regehr, 2014), this distinct and separate regulation of spontaneous release provides a mechanism to modulate a wide range of cellular functions independent of afferent action potentials. TRPV1 consequently serves as an essential modulation target because it provides a calcium source to drive spontaneous release independent from afferent activity or voltage.

It is not clear how spontaneous release of glutamate in the NTS and the modulatory differences that we observe in evoked glutamate translates to physiological functions. Both TRPV1 and $\mathrm{CB}_{1}$ in the NTS modify basic homeostatic functions. TRPV1 plays a key role in neonatal respiratory regulation with small temperature shifts within the NTS (Xia et al., 2011). $\mathrm{CB}_{1}$ receptors broadly inhibit cardiovascular and gastrointestinal functions (Van Sickle et al., 2003; Brozoski et al., 2005; Evans et al., 2007). The importance of endocannabinoid/endovanilloid signaling might be amplified or have more pronounced consequences in disease states in which there are chronic shifts in lipid profiles (e.g., hyperglycemia and obesity; Matias et al., 2008). The $\mathrm{CB}_{1} /$ TRPV1 mechanisms and their interactions with lipid signaling may have potential implications in multisystem, homeostatic dysfunction that accompanies inflammatory states (Pingle et al., 2007), obesity (Marshall et al., 2013), and/or early development (Xia et al., 2011).

\section{References}

Andresen MC, Peters JH (2008) Comparison of baroreceptive to other afferent synaptic transmission to the solitary tract nucleus. Am J Physiol Heart Circ Physiol 295:H2032-H2042. CrossRef Medline

Andresen MC, Hofmann ME, Fawley JA (2012) Invited review: the unsilent majority-TRPV1 drives "spontaneous" transmission of unmyelinated primary afferents within cardiorespiratory NTS. Am J Physiol Regul Integr Comp Physiol 303:R1207-R1216. CrossRef Medline

Appleyard SM, Bailey TW, Doyle MW, Jin YH, Smart JL, Low MJ, Andresen MC (2005) Proopiomelanocortin neurons in nucleus tractus solitarius are activated by visceral afferents: regulation by cholecystokinin and opioids. J Neurosci 25:3578-3585. CrossRef Medline

Atasoy D, Ertunc M, Moulder KL, Blackwell J, Chung C, Su J, Kavalali ET (2008) Spontaneous and evoked glutamate release activates two populations of NMDA receptors with limited overlap. J Neurosci 28:1015110166. CrossRef Medline

Bailey TW, Hermes SM, Andresen MC, Aicher SA (2006a) Cranial visceral afferent pathways through the nucleus of the solitary tract to caudal ventrolateral medulla or paraventricular hypothalamus: target-specific synaptic reliability and convergence patterns. J Neurosci 26:11893-11902. CrossRef Medline

Bailey TW, Jin YH, Doyle MW, Smith SM, Andresen MC (2006b) Vasopressin inhibits glutamate release via two distinct modes in the brainstem. J Neurosci 26:6131-6142. CrossRef Medline

Bisogno T, Melck D, Bobrov MYu, Gretskaya NM, Bezuglov VV, De Petrocellis L, Di Marzo V (2000) N-acyl-dopamines: novel synthetic CB(1) 
cannabinoid-receptor ligands and inhibitors of anandamide inactivation with cannabimimetic activity in vitro and in vivo. Biochem J 351:817824. CrossRef Medline

Brown DA, Sihra TS (2008) Presynaptic signaling by heterotrimeric G-proteins. In: Pharmacology of neurotransmitter release, Ed 184 (Südhof TC, Starke K, eds), pp 207-260. Berlin: Springer.

Brown SP, Safo PK, Regehr WG (2004) Endocannabinoids inhibit transmission at granule cell to Purkinje cell synapses by modulating three types of presynaptic calcium channels. J Neurosci 24:5623-5631. CrossRef Medline

Brozoski DT, Dean C, Hopp FA, Seagard JL (2005) Uptake blockade of endocannabinoids in the NTS modulates baroreflex-evoked sympathoinhibition. Brain Res 1059:197-202. CrossRef Medline

Bucurenciu I, Kulik A, Schwaller B, Frotscher M, Jonas P (2008) Nanodomain coupling between $\mathrm{Ca}(2+)$ channels and $\mathrm{Ca}(2+)$ sensors promotes fast and efficient transmitter release at a cortical GABAergic synapse. Neuron 57:536-545. CrossRef Medline

Castillo PE, Younts TJ, Chávez AE, Hashimotodani Y (2012) Endocannabinoid signaling and synaptic function. Neuron 76:70-81. CrossRef Medline

Caterina MJ (2007) Transient receptor potential ion channels as participants in thermosensation and thermoregulation. Am J Physiol Regul Integr Comp Physiol 292:R64-R76. Medline

Caterina MJ, Julius D (2001) The vanilloid receptor: A molecular gateway to the pain pathway. Annu Rev Neurosci 24:487-517. CrossRef Medline

Cristino L, de Petrocellis L, Pryce G, Baker D, Guglielmotti V, Di Marzo V (2006) Immunohistochemical localization of cannabinoid type 1 and vanilloid transient receptor potential vanilloid type 1 receptors in the mouse brain. Neuroscience 139:1405-1415. CrossRef Medline

Cristino L, Starowicz K, De Petrocellis L, Morishita J, Ueda N, Guglielmotti V, Di Marzo V (2008) Immunohistochemical localization of anabolic and catabolic enzymes for anandamide and other putative endovanilloids in the hippocampus and cerebellar cortex of the mouse brain. Neuroscience 151:955-968. CrossRef Medline

De Petrocellis L, Harrison S, Bisogno T, Tognetto M, Brandi I, Smith GD, Creminon C, Davis JB, Geppetti P, Di Marzo V (2001) The vanilloid receptor (VR1)-mediated effects of anandamide are potently enhanced by the cAMP-dependent protein kinase. J Neurochem 77:1660-1663. CrossRef Medline

Di Marzo V, De Petrocellis L (2012) Why do cannabinoid receptors have more than one endogenous ligand? Philos Trans R Soc Lond B Biol Sci 367:3216-3228. CrossRef Medline

Di Marzo V, Bisogno T, Melck D, Ross R, Brockie H, Stevenson L, Pertwee R, De Petrocellis L (1998) Interactions between synthetic vanilloids and the endogenous cannabinoid system. FEBS Lett 436:449-454. CrossRef Medline

Doyle MW, Andresen MC (2001) Reliability of monosynaptic transmission in brain stem neurons in vitro. J Neurophysiol 85:2213-2223. Medline

Doyle MW, Bailey TW, Jin YH, Andresen MC (2002) Vanilloid receptors presynaptically modulate visceral afferent synaptic transmission in nucleus tractus solitarius. J Neurosci 22:8222-8229. Medline

Evans RM, Scott RH, Ross RA (2007) Chronic exposure of sensory neurones to increased levels of nerve growth factor modulates CB1/TRPV1 receptor crosstalk. Br J Pharmacol 152:404-413. CrossRef Medline

Fawley JA, Peters JH, Andresen MC (2011) GABAB-mediated inhibition of multiple modes of glutamate release in the nucleus of the solitary tract. J Neurophysiol 106:1833-1840. CrossRef Medline

Huang SM, Bisogno T, Trevisani M, Al-Hayani A, De Petrocellis L, Fezza F, Tognetto M, Petros TJ, Krey JF, Chu CJ, Miller JD, Davies SN, Geppetti P, Walker JM, Di Marzo V (2002) An endogenous capsaicin-like substance with high potency at recombinant and native vanilloid VR1 receptors. Proc Natl Acad Sci U S A 99:8400-8405. CrossRef Medline

Jin YH, Bailey TW, Li BY, Schild JH, Andresen MC (2004) Purinergic and vanilloid receptor activation releases glutamate from separate cranial afferent terminals. J Neurosci 24:4709-4717. CrossRef Medline

Kaeser PS, Regehr WG (2014) Molecular mechanisms for synchronous, asynchronous, and spontaneous neurotransmitter release. Annu Rev Physiol 76:333-363. CrossRef Medline

Katz B (1971) Quantal mechanism of neural transmitter release. Science 173:123-126. CrossRef Medline

Laaris N, Weinreich D (2007) Prostaglandin E2 depresses solitary tract- mediated synaptic transmission in the nucleus tractus solitarius. Neuroscience 146:792-801. CrossRef Medline

Li BY, Feng B, Tsu HY, Schild JH (2007) Unmyelinated visceral afferents exhibit frequency dependent action potential broadening while myelinated visceral afferents do not. Neurosci Lett 421:62-66. CrossRef Medline

Marinelli S, Di Marzo V, Berretta N, Matias I, Maccarrone M, Bernardi G, Mercuri NB (2003) Presynaptic facilitation of glutamatergic synapses to dopaminergic neurons of the rat substantia nigra by endogenous stimulation of vanilloid receptors. J Neurosci 23:3136-3144. Medline

Marinelli S, Di Marzo V, Florenzano F, Fezza F, Viscomi MT, van der Stelt M, Bernardi G, Molinari M, Maccarrone M, Mercuri NB (2007) $\mathrm{N}$-Arachidonoyl-dopamine tunes synaptic transmission onto dopaminergic neurons by activating both cannabinoid and vanilloid receptors. Neuropsychopharmacology 32:298-308. CrossRef Medline

Marshall NJ, Liang L, Bodkin J, Dessapt-Baradez C, Nandi M, Collot-Teixeira S, Smillie SJ, Lalgi K, Fernandes ES, Gnudi L, Brain SD (2013) A role for TRPV1 in influencing the onset of cardiovascular disease in obesity. Hypertension 61:246-252. CrossRef Medline

Matias I, Petrosino S, Racioppi A, Capasso R, Izzo AA, Di Marzo V (2008) Dysregulation of peripheral endocannabinoid levels in hyperglycemia and obesity: effect of high fat diets. Mol Cell Endocrinol 286:S66-S78. CrossRef Medline

Matta JA, Ahern GP (2011) TRPV1 and synaptic transmission. Curr Pharm Biotechnol 12:95-101. CrossRef Medline

McDougall SJ, Andresen MC (2013) Independent transmission of convergent visceral primary afferents in the solitary tract nucleus. J Neurophysiol 109:507-517. CrossRef Medline

McDougall SJ, Peters JH, Andresen MC (2009) Convergence of cranial visceral afferents within the solitary tract nucleus. J Neurosci 29:1288612895. CrossRef Medline

McKinney RA, Capogna M, Dürr R, Gähwiler BH, Thompson SM (1999) Miniature synaptic events maintain dendritic spines via AMPA receptor activation. Nat Neurosci 2:44-49. CrossRef Medline

Melom JE, Akbergenova Y, Gavornik JP, Littleton JT (2013) Spontaneous and evoked release are independently regulated at individual active sones. J Neurosci 33:17253-17263. CrossRef Medline

Mendelowitz D, Reynolds PJ, Andresen MC (1995) Heterogeneous functional expression of calcium channels at sensory and synaptic regions in nodose neurons. J Neurophysiol 73:872-875. Medline

Neher E, Sakaba T (2008) Multiple roles of calcium ions in the regulation of neurotransmitter release. Neuron 59:861-872. CrossRef Medline

Nelson ED, Kavalali ET, Monteggia LM (2008) Activity-dependent suppression of miniature neurotransmission through the regulation of DNA methylation. J Neurosci 28:395-406. CrossRef Medline

Patil M, Patwardhan A, Salas MM, Hargreaves KM, Akopian AN (2011) Cannabinoid receptor antagonists AM251 and AM630 activate TRPA1 in sensory neurons. Neuropharmacology 61:778-788. CrossRef Medline

Peled ES, Newman ZL, Isacoff EY (2014) Evoked and spontaneous transmission favored by distinct sets of synapses. Curr Biol 24:484-493. CrossRef Medline

Pertwee RG, Howlett AC, Abood ME, Alexander SPH, Di Marzo V, Elphick MR, Greasley PJ, Hansen HS, Kunos G, Mackie K, Mechoulam R, Ross RA (2010) International Union of Basic and Clinical Pharmacology. LXXIX. Cannabinoid receptors and their ligands: beyond CB1 and CB2. Pharmacol Rev 62:588-631. CrossRef Medline

Peters JH, McDougall SJ, Kellett DO, Jordan D, Llewellyn-Smith IJ, Andresen MC (2008) Oxytocin enhances cranial visceral afferent synaptic transmission to the solitary tract nucleus. J Neurosci 28:11731-11740. CrossRef Medline

Peters JH, McDougall SJ, Fawley JA, Smith SM, Andresen MC (2010) Primary afferent activation of thermosensitive TRPV1 triggers asynchronous glutamate release at central neurons. Neuron 65:657-669. CrossRef Medline

Pingle SC, Matta JA, Ahern GP (2007) Capsaicin receptor: TRPV1 a promiscuous TRP channel. In: Transient receptor potential (TRP) channels, Ed 179 (Flockerzi V, Nilius B, eds), pp 155-171. Berlin: Springer.

Sara Y, Virmani T, Deák F, Liu X, Kavalali ET (2005) An isolated pool of vesicles recycles at rest and drives spontaneous neurotransmission. Neuron 45:563-573. CrossRef Medline

Sara Y, Bal M, Adachi M, Monteggia LM, Kavalali ET (2011) Use-dependent 
AMPA receptor block reveals segregation of spontaneous and evoked glutamatergic neurotransmission. J Neurosci 31:5378-5382. CrossRef Medline

Schild JH, Clark JW, Hay M, Mendelowitz D, Andresen MC, Kunze DL (1994) A- and C-type nodose sensory neurons: model interpretations of dynamic discharge characteristics. J Neurophysiol 71:2338-2358. Medline

Shoudai K, Peters JH, McDougall SJ, Fawley JA, Andresen MC (2010) Thermally active TRPV1 tonically drives central spontaneous glutamate release. J Neurosci 30:14470-14475. CrossRef Medline

Südhof TC (2013) Neurotransmitter release: The last millisecond in the life of a synaptic vesicle. Neuron 80:675-690. CrossRef Medline

Van Sickle MD, Oland LD, Mackie K, Davison JS, Sharkey KA (2003) Delta9-tetrahydrocannabinol selectively acts on CB1 receptors in specific regions of dorsal vagal complex to inhibit emesis in ferrets. Am J Physiol Gastrointest Liver Physiol 285:G566-G576. Medline
Voorn P, Buijs RM (1983) An immuno-electronmicroscopical study comparing vasopressin, oxytocin, substance $\mathrm{P}$ and enkephalin containing nerve terminals in the nucleus of the solitary tract of the rat. Brain Res 270:169-173. CrossRef Medline

Wasser CR, Kavalali ET (2009) Leaky synapses: Regulation of spontaneous neurotransmission in central synapses. Neuroscience 158:177-188. CrossRef Medline

Xia L, Bartlett D Jr, Leiter JC (2011) TRPV1 channels in the nucleus of the solitary tract mediate thermal prolongation of the LCR in decerebrate piglets. Respir Physiol Neurobiol 176:21-31. CrossRef Medline

Yoon EJ, Gerachshenko T, Spiegelberg BD, Alford S, Hamm HE (2007) Gbetagamma interferes with $\mathrm{Ca} 2+$-dependent binding of synaptotagmin to the soluble $\mathrm{N}$-ethylmaleimide-sensitive factor attachment protein receptor (SNARE) complex. Mol Pharmacol 72:1210-1219. CrossRef Medline 